\title{
Prevalence and Risk Factors of Intestinal Helminthiasis in Remote Mountainous Villages of Northern Lao PDR: A Cross-Sectional Study
}

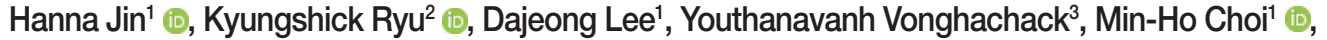 \\ Sung-Tae Hong ${ }^{1}\left[{ }^{\circ}\right.$, Hyun Beom Song ${ }^{1,4, *}$ (D) \\ 'Department of Tropical Medicine and Parasitology, Seoul National University College of Medicine, and Institute of Endemic Diseases, Seoul National \\ University Medical Research Center, Seoul 03080, Korea; ${ }^{2}$ Chonbuk National University Medical School, Chonju 54907, Korea; ${ }^{3}$ Savannakhet \\ Provincial Health Department, Savannakhet, Lao PDR, ${ }^{4}$ Department of Biomedical Sciences, Seoul National University Graduate School, \\ Seoul 03080, Korea
}

\begin{abstract}
Helminth infections are prevalent in Lao People's Democratic Republic (Lao PDR). This study aimed at determining the prevalence and risk factors of intestinal helminthiasis in remote mountainous villages of northern Lao PDR. During the dry season in January 2017, a cross-sectional survey was conducted in 3 remote mountainous villages in Oudomxay province, Lao PDR. Villagers older than 18 years of age who agreed to submit stool samples or undergo an interview, were recruited. Stool samples from 198 individuals were examined by the Kato-Katz method, and a questionnaire surveyed 161 individuals among them. Univariable and multivariable logistic regression analyses were used to identify risk factors associated with the intestinal helminthiasis. An overall prevalence of intestinal helminthiasis was $75.8 \%$. Hookworm infection was the most common (63.1\%), followed by Opisthorchis viverrini/minute intestinal flukes (17.7\%), Taenia spp. (15.2\%), Trichuris trichiura (2.0\%), Ascaris lumbricoides (1.5\%), and Enterobius vermicularis (1.0\%). Questionnaire analysis revealed sex (male) and absence of latrine to be significant risk factors for hookworm infection and consumption of raw meat for taeniasis. These results suggest that the mountainous area in northern Lao PDR has a different composition of helminth infections from other studies conducted in Lao PDR; a high prevalence of hookworm infection and taeniasis and low prevalence of $T$. trichiura and $A$. lumbricoides infections were observed. Also, liver flukes or intestinal flukes were similarly prevalent in the mountainous area.
\end{abstract}

Key words: Taenia sp., intestinal helminth, hookworm, risk factor, Lao PDR

\section{INTRODUCTION}

Helminth infections are prevalent in Lao People's Democratic Republic (Lao PDR), and according to the nationwide survey of primary school children conducted from 2000 to 2002, the overall prevalence of intestinal helminth infection was $61.9 \%$ [1]. In each province, the prevalence ranged from $27.5 \%$ to $96.0 \%$, and compositions of helminth infection differed widely. Another nationwide survey conducted from 2007 to 2011 revealed that the overall prevalence was $71.9 \%$ [2]. Most of the positive cases were Opisthorchis viverrini and minute intestinal flukes (Ov/MIF) infection (55.6\%), while cases

- Received 23 December 2020, revised 5 April 2021, accepted 8 April 2021.

*Corresponding author (hbsong@snu.ac.kr)

(c) 2021. Korean Society for Parasitology and Tropical Medicine

This is an Open Access article distributed under the terms of the Creative Commons Attribution Non-Commercial License (https://creativecommons.org/licenses/by-nc/4.0) which permits unrestricted non-commercial use, distribution, and reproduction in any

medium, provided the original work is properly cited. positive for Ov/MIF infection were only $9.3 \%$ for individuals from northern Lao PDR including Phongsaly, Luang Prabang and Xieng Khouang province in the study. Instead of Ov/MIF, hookworm infection was the most prevalent (39.5\%) in northern Lao PDR.

Taeniasis is another parasitic infection characterized by a high degree of variation in different groups. A nationwide survey of schoolchildren reported the prevalence of taeniasis was $0.6 \%[1]$, while another nationwide survey of individuals with unspecified age reported the prevalence was $4.8 \%$, ranging from 0 to $8.6 \%$ in different provinces [2]. In Champasack Province in southern Lao PDR, the prevalence was as low as $0.1 \%[3]$.

Studies conducted in northern Lao PDR revealed a high prevalence of hookworm infection and taeniasis. A survey conducted in Oudomxay province located in the northern mountainous area showed the prevalence of hookworm infection and taeniasis was more than 50\% [4] and more than 13\% [5], 
respectively. Another survey in Phongsaly province, a mountainous area bordering Vietnam, revealed hookworm infection and taeniasis prevalence of $56 \%$ and $18 \%$, respectively [6].

This study aimed to investigate helminth infection, especially taeniasis, in the remote mountainous area in northern Lao PDR, where intervention was not conducted before. A crosssectional survey was conducted in 3 villages in the Beng District of Oudomxay province to assess the prevalence of helminth infections and their risk factors.

\section{MATERIALS AND METHODS}

\section{Ethics statement}

The study was approved by the Lao National Ethics Committee for Health Research (NECHR), Ministry of Health, Vientiane, Lao PDR (reference No. 014/NECHR). All procedures were explained to provincial, district, and village authorities, and their approval was obtained. Study participants were informed on study procedures, benefits, and risks of the study as well as their rights to withdraw at any time. Those infected with helminth were treated with a single $400 \mathrm{mg}$ dose of albendazole and $40 \mathrm{mg} / \mathrm{kg}$ of praziquantel free of charge, according to the Lao national treatment guidelines [7].

\section{Study area}

The study was conducted in 3 villages, Namcheem, Pasak, and Nangua, which are situated in a remote mountainous region of Beng District, Oudomxay Province, Lao PDR (Fig. 1). Water supply is from small streams nearby, and the majority of residents were farmers. The Hmong ethnic group formed the majority of the population in Namcheem and Pasak villages and the Leu ethnic group in Nangua village. No prior mass drug administration was performed in these villages.

\section{Study design and field procedure}

The present study was performed in the dry season in January 2017. Participants who were older than 18 and agreed to submit stool samples and/or undergo interviews, were recruited. They were fully explained by personnel who can communicate with the residents in their local languages before the study. The questionnaire, translated into the villager's mother tongue, was used to assess the villager's lifestyle, including demographic information, medical history, eating habits, ownership of livestock, and hygiene. The interviews were conducted by trained personnel, and the questionnaires were filled out by

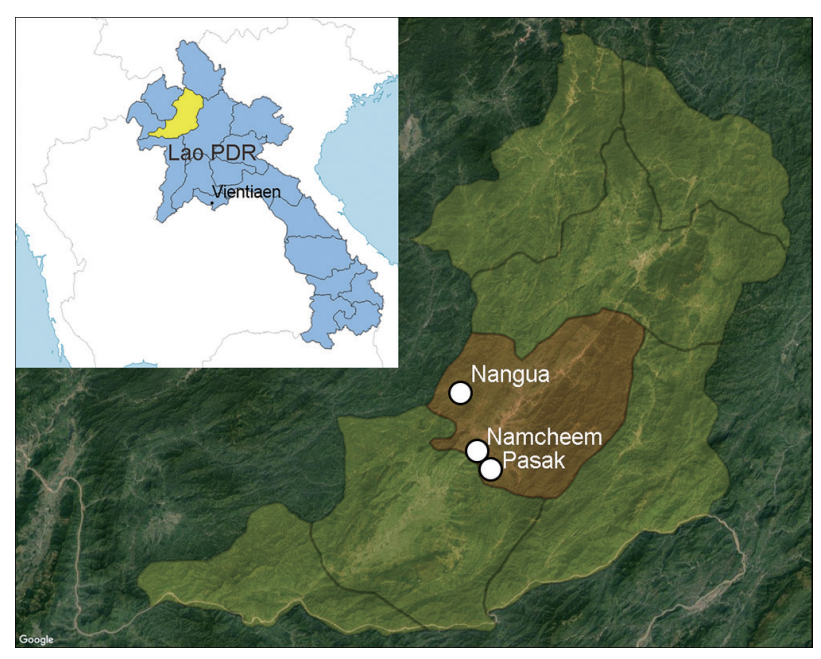

Fig. 1. Study villages (white circles) in Beng district (brown), Oudomxay, Lao PDR (images from Google Map).

them. Stool samples of 198 people were collected, and 171 individuals underwent interviews. Complete sets of stool samples and interviews from 161 individuals were available for further evaluation. The study protocol was reviewed and approved by the Lao National Ethics Committee for Health Research (NECHR), Ministry of Health, Vientiane, Lao PDR (Trial No. 014/NECHR).

\section{Stool examination}

A single stool sample was collected from each participant, and the specimens were examined by the Kato-Katz (KK) method [8]. Briefly, stool samples were filtered through a fine mesh into templates that hold $41.7 \mathrm{mg}$ per test. Each fecal sample was then covered by a cellophane strip, which was dipped in glycerol and malachite green in advance, and was then pressed gently and evenly over a slide glass. One slide was prepared from each stool specimen to be examined under the microscope.

\section{Statistical analysis}

The categorical data were analyzed by the Chi-square test or the Fisher exact test. Risk factors were evaluated by estimating the odds ratio by logistic regression analysis. In the case of zero egg count, Firth logistic regression was utilized. Statistical analyses were conducted using SPSS 23.0 (SPSS Inc., Chicago, Illinois, USA) except for Firth logistic regression, which was conducted using R software [9]. 


\section{RESULTS}

\section{Characteristics of the study population}

Stool samples from 198 people were included for analysis, and 97 participants $(49.0 \%)$ were male with the mean age of $46.8 \pm 15.3$ years (range: $19-89$ ). Mean ages by sex were $47.7 \pm 15.2$ years (range: $19-89$ ) for males and $46.0 \pm 15.4$ years (range: 18-78) for females. Among 198 participants, 161 people responded to the questionnaire and were included for risk factor analysis. Among them, 52.2\% were male, and the mean age was $49.2 \pm 14.6$ years (range: $19-89)$. Mean ages by sex were $48.5 \pm 15.6$ years (range: $19-89$ ) for males and $50.0 \pm 13.5$ years (range: $19-78$ ) for females.

\section{Prevalence of helminth infection}

Intestinal helminth infections were prevalent in the study population, and the cumulative prevalence was $75.8 \%$. The eggs of hookworm, Opisthorchis viverrini and minute intestinal flukes (Ov/MIF), and Taenia spp. were detected in 63.1\%, $17.7 \%$, and $15.2 \%$ of stool samples, respectively (Table 1 ). In contrast, egg positive rates of Ascaris lumbricoides, Trichuris trichiura, and Enterobius vermicularis, were less than 2.0\% (Table 1). The cumulative prevalence of intestinal helminths was not significantly different between males (78.4\%) and females (73.3\%) $(P=0.404)$, but hookworm was more prevalent in males $(71.1 \%)$ than in females $(55.4 \%)(P=0.022)$.

Multiparasitism of up to 3 species was detected: more than a quarter of the infected people (29.3\%) were positive for 2 helminth species or more (Table 2). There was no significant difference between males and females in multiparasitism $(P=0.817)$. Among individuals with multiparasitism, the most common coinfection was with hookworm and Ov/MIF (47.7\%). Among Ov/MIF-infected individuals, 60\% were coinfected with hookworm. Among 21 individuals co-infected with hookworm and Ov/MIF, 5 individuals were additionally positive for another helminth species: 4 for Taenia spp. and one for E. vermicularis.

Regarding taeniasis, a history of the expulsion of proglottids was also surveyed to detect tapeworm carriers [10,11]. Among 161 individuals interviewed, 123 individuals had a history of proglottids expulsion during defecation, and $17.1 \%$ of them were egg-positive for Taenia spp., whereas only 7.9\% among individuals without a history of proglottids expulsion were egg-positive for Taenia spp.

\section{Risk factors for hookworm infection and taeniasis}

Among the study population, 161 individuals were interviewed to evaluate risk factors for helminth infection. After an initial univariate logistic regression analysis for predicting any positivity for helminth infection, the following variables were included in the multivariate logistic regression: sex, age, ethnicity, food consumption habits, livestock, and presence of latrine. According to the multivariate logistic regression analysis, males were more susceptible to hookworm infection compared to females $(\mathrm{OR}=2.120, P=0.025$; Table 3$)$. The presence of latrine decreased the risk for hookworm infection $(\mathrm{OR}=0.278, P=0.006$; Table 3$)$, and it was closely related to other variables found related by univariate logistic analysis: ethnicity, the consumption of fermented vegetables, and ownership of pig or duck, respectively $(P<0.001)$. In contrast, the consumption of raw meat was the only variable related to taeniasis ( $O R=11.750, P=0.011$; Table 3$)$. All other variables, including the presence of latrine or raising pigs without caging,

Table 2. Distribution of mixed helminth infections in Beng district, 2017

\begin{tabular}{lccc}
\hline & Total $(n=198)$ & Male $(n=97)$ & Female $(n=101)$ \\
\hline One species & $53.5 \%$ & $55.7 \%$ & $51.5 \%$ \\
Two species & $19.7 \%$ & $20.6 \%$ & $18.8 \%$ \\
Three species & $2.5 \%$ & $2.1 \%$ & $3.0 \%$ \\
\hline
\end{tabular}

Table 1. Prevalence of helminth infection in northern Lao PDR, Beng district, 2017

\begin{tabular}{|c|c|c|c|c|}
\hline Parasite & Total $(n=198)$ & Male $(n=97)$ & Female $(n=101)$ & $P$-value \\
\hline Hookworm & $63.1 \%$ & $71.1 \%$ & $55.4 \%$ & 0.022 \\
\hline Taenia spp. & $15.2 \%$ & $13.4 \%$ & $16.8 \%$ & 0.501 \\
\hline Trichuris trichiura & $2.0 \%$ & $3.1 \%$ & $1.0 \%$ & $0.361^{b}$ \\
\hline Enterobius vermicularis & $1.0 \%$ & $1.0 \%$ & $1.0 \%$ & $1.000^{b}$ \\
\hline Ascaris lumbricoides & $1.5 \%$ & $1.0 \%$ & $2.0 \%$ & $1.000^{b}$ \\
\hline Cumulative prevalence & $75.8 \%$ & $78.4 \%$ & $73.3 \%$ & 0.404 \\
\hline
\end{tabular}

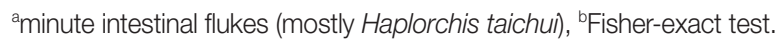




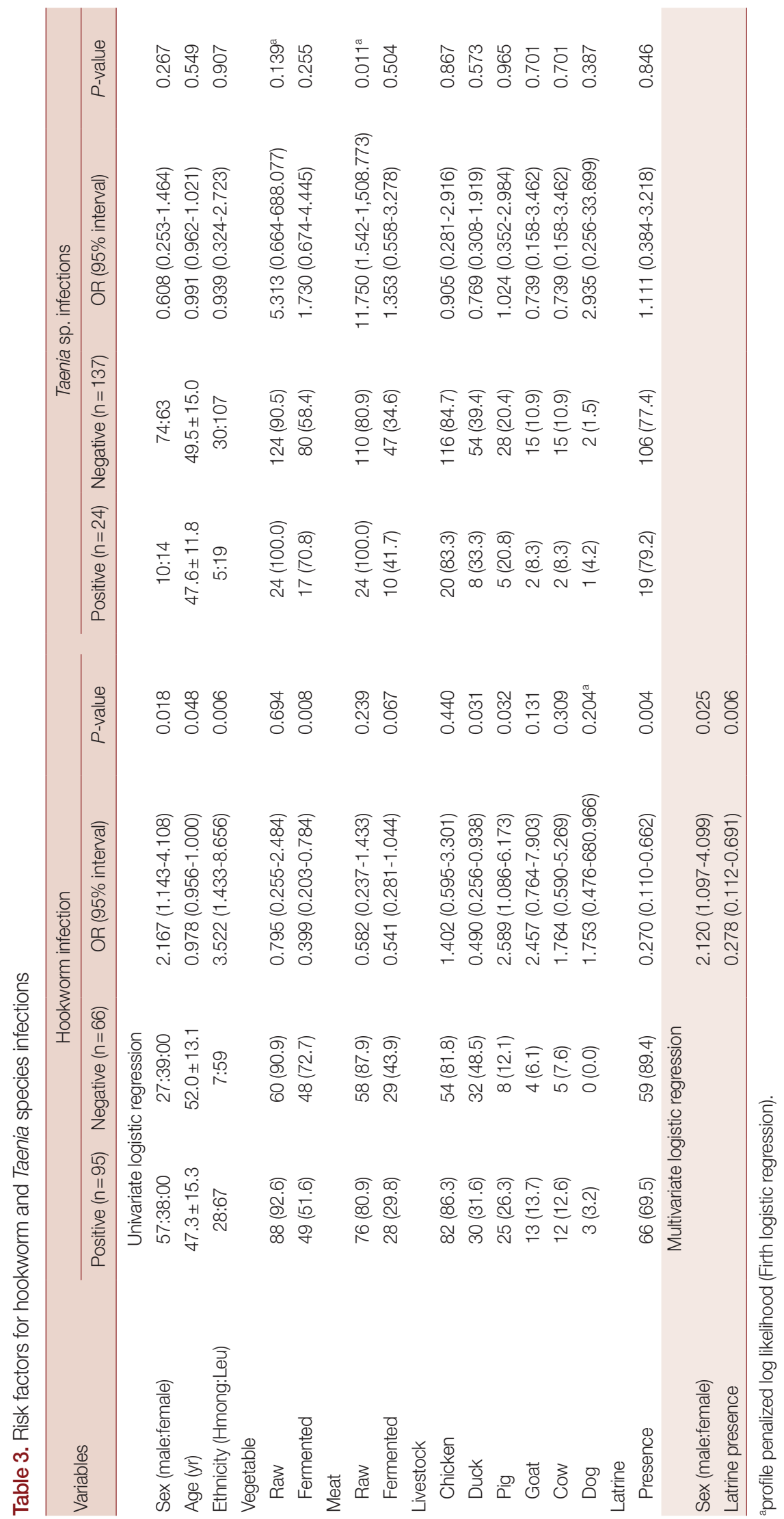


were not related. Most of the open defecation and free-range pig farming was found in the Hmong ethnic group, but there was no difference in taeniasis prevalence between the 2 ethnic groups.

\section{DISCUSSION}

In this study, we investigated helminth infections in the remote mountainous area in northern Lao PDR by analyzing stool samples from 198 people. The cumulative egg positive rate was $75.8 \%$, among which $29.3 \%$ accounts for multiparasitism. Hookworm was the most common helminth with a prevalence of $63.1 \%$. Males had a higher risk for hookworm infection than females, and the presence of latrine decreased the risk of hookworm infection. Taeniasis was detected in $15.2 \%$ of the individuals, and consumption of raw meat was found to increase the risk of the infection.

The prevalence of hookworm infection in the present study was $63.1 \%$, which was higher than in the previous study, in which the prevalence was $12.3 \%$ among primary school children in Oudomxay [1]. As the prevalence of hookworm infection is known to increase with age [12], the high prevalence in this study could be associated with the age composition of the study subjects. Besides, the prompt preparation and examination of stool samples might have enabled optimal evaluation of the hookworm eggs. In contrast to the previous study where fecal specimens were collected and stored in refrigerators prior to examination [1], we could evaluate the stool samples within 12 hours after collection, leaving no time for hatch of hookworm eggs. Prevalence estimates by delayed stool examination often measured lower than actual hookworm prevalence. Although the KK method cannot differentiate the species of hookworms, Necator americanus might be the dominant hookworm species in this area, according to the previous study [4].

The lifespan of hookworms is estimated to be 5-7 years [13]. Due to its relatively short lifespan, persistent hookworm infection can only be established by repeated exposure to soil contaminated by the filariform larvae of hookworm [14]. In accordance with other studies $[15,16]$, the presence of latrine was found protective against hookworm infection in this study. However, more than half of individuals having latrines at their houses were still positive for hookworm infection in this study, which leads to the assumption that the defecation site was not the only source of exposure. As the villages in this study rely mainly on agriculture for their living, exposure to the soil during farming could be another source of infection, which is supported by the finding that males had higher risk for hookworm infection than females in this study. The previous study suggested that dogs had a role in hookworm transmission to humans as N. americanus has been found in dogs as well as Ancylostoma ceylanicum as a dominant species [4]. These risk factors should be carefully modulated to control hookworm infection because a previous mass drug administration in Lao PDR showed a significant effect on the prevalence of A. lumbricoides and T. trichiura but minimal effect on hookworm prevalence [17]. It is necessary to strengthen STH control programs, especially paying more attention to control hookworm infections in Lao PDR.

The overall prevalence of Ov/MIF infection in Lao PDR was found to be $40 \%$ with a higher infection rate in southern provinces, according to a study conducted in 1992 [18]. In northern Lao PDR, the prevalence varied widely, ranging from $0 \%$ [19] to $15 \%[20,21]$. The highest prevalence of Ov/MIF infections in northern Lao PDR was reported in the villages where rivers run through [20]. Conducting a study with villages in high altitudes and long distances from freshwater bodies, we expected a lower prevalence of Ov/MIF infection, as shown in another study [22]; however, the prevalence of Ov/MIF infection in this study was rather high (17.7\%). Further evaluation of other risk factors, including raw fish consumption, and survey of the infection status of fish are needed to elaborate on our findings.

The prevalence of taeniasis is known to differ between adults and children. In one study conducted in Oudomxay showed that the prevalence was $1.2 \%$ in children aged 6-11 years [1]. Another study conducted in southern Lao PDR, the prevalence was about $6 \%$ in individuals below 15 years of age, while it was higher among adult age groups [23]. The prevalence of taeniasis is the lowest in young children, and this is probably due to lower prevalence of the risky behavior of consuming raw meat and less cumulative exposure to the raw meat than adults [24]. In this study, where individuals older than 18 were investigated, the prevalence of taeniasis was $15.2 \%$.

The consumption of raw meat was the only factor that increases the risk of taeniasis. Although there were villages where open defecation and free-range pig farming were relatively frequent, the prevalence was not high in those villages with more chances of transmission. Besides, 24 individuals who did not consume raw meat were found egg negative for Taenia spp. 
These findings suggest that consumption of well-cooked meat can prevent taeniasis even in endemic areas.

The prevalence of A. lumbricoides and T. trichiura in this study was only $1.5 \%$ and $2.0 \%$, respectively, which is extremely low compared to previous studies conducted in the area. The egg positive rate of A. lumbricoides and T. trichiura was $62.6 \%$ and $39.8 \%$ in $2000-2002$ [1], and $24.5 \%$ and $45.6 \%$ in another survey in 2009 [4], respectively. In a neighboring province, it decreased to $33.8 \%$ and $27.7 \%$ in 2008 , and $7.5 \%$ and $16.5 \%$ in another neighboring province in 2011 [2], respectively. Although the target population of previous studies was not the same as the present study, the prevalence showed a tendency to decrease, and this study showed a much lower prevalence of A. lumbricoides and T. trichiura. The discrepancy in prevalence results from the difference in the age composition of the study population: all participants were older than 18 in this study. Children aged 5-15 years are risk groups of soil-transmitted helminths, including A. lumbricoides and T. trichiura [13], but this age group was not included in this survey, as taeniasis was the major target for the study.

This study has limitations in evaluating the prevalence of intestinal helminthiasis. Although the KK method used in this study is the standard technique to detect intestinal parasites, it is challenging to identify O. viverrini eggs from MIF eggs [22]. As Haplorchis sp. was more common than O. viverrini in northern Lao PDR $[20,25,26]$, most of the Ov/MIF infection in this study was considered as MIF infection. Also, single KK smear was read in this study instead of $2 \mathrm{KK}$ smears, and eggs were not counted, as the present study was mainly focused on investigating the prevalence of taeniasis and proglottids were recovered from the infected persons after praziquantel treatment. The KK method is less sensitive in the detection of taeniasis [27]. In this study, $76.4 \%$ of the study population had a history of proglottids expulsion during defecation, but the prevalence of taeniasis evaluated by the KK method was only $15.2 \%$. It is known that repeated examinations can improve the sensitivity [28], and copro-antigen and copro-DNA detection can increase the sensitivity and specificity for detecting tapeworm carriers [29]. Indeed, one study conducted in northern Lao PDR revealed $27.9 \%$ positivity by copro-antigen ELISA on fecal samples [30], which is much higher than the data presented in this study.

Although the sample size for the study was not considered large, it was demonstrated that a high prevalence of hookworm, Taenia spp., and Ov/MIF infection were observed in the remote mountainous areas in northern Lao PDR, where no prior intervention such as mass drug administration was conducted. Risk factor analysis revealed that being an adult male and having no latrine markedly increase the risk of hookworm infection, while consuming raw meat increases that of taeniasis. Appropriate programs to control intestinal helminth infection are required in remote mountainous villages of northern Lao PDR, and interventions on latrine availability and health education for changing meat consumption behavior should be integrated to the control programs.

\section{ACKNOWLEDGMENTS}

We are grateful to the residents of the study villages and to Mr. Santhavisouk Sengchanda, Ms. Olanath Phenedinvay and Ms. Keo Oudone from Faculty of Basic Sciences, University of Health Sciences, Lao PDR and staffs from Provincial Health Department and Beng district hospital, Oudomxay Province, Lao PDR for their assistance in collecting fecal specimens and preparing the KK smears. This study was supported by Dr. LEE Jong-wook-Seoul Project (800-20170058), by SNUCM Undergraduate Research Program, and by Seoul National University Hospital.

\section{CONFLICT OF INTEREST}

We have no conflict of interest related to this work.

\section{REFERENCES}

1. Rim HJ, Chai JY, Min DY, Cho SY, Eom KS, Hong SJ, Sohn WM, Yong TS, Deodato G, Standgaard H, Phommasack B, Yun CH, Hoang EH. Prevalence of intestinal parasite infections on a national scale among primary schoolchildren in Laos. Parasitol Res 2003; 91: 267-272. https://doi.org/10.1007/s00436-003-0963-x

2. Eom KS, Yong TS, Sohn WM, Chai JY, Min DY, Rim HJ, Jeon HK, Banouvong V, Insisiengmay B, Phommasack B. Prevalence of helminthic infections among inhabitants of Lao PDR. Korean J Parasitol 2014; 52: 51-56. https://doi.org/10.3347/kjp.2014.52.1.51

3. Vonghachack Y, Odermatt P, Taisayyavong K, Phounsavath S, Akkhavong K, Sayasone S. Transmission of Opisthorchis viverrini, Schistosoma mekongi and soil-transmitted helminthes on the Mekong Islands, Southern Lao PDR. Infect Dis Poverty 2017; 6: 131. https://doi.org/10.1186/s40249-017-0343-x

4. Conlan JV, Khamlome B, Vongxay K, Elliot A, Pallant L, Sripa B, Blacksell SD, Fenwick S, Thompson RC. Soil-transmitted helminthiasis in Laos: a community-wide cross-sectional study of hu- 
mans and dogs in a mass drug administration environment. Am J Trop Med Hyg 2012; 86: 624-634. https://doi.org/10.4269/ajtmh.2012.11-0413

5. Conlan JV, Vongxay K, Khamlome B, Dorny P, Sripa B, Elliot A, Blacksell SD, Fenwick S, Thompson RC. A cross-sectional study of Taenia solium in a multiple taeniid-endemic region reveals competition may be protective. Am J Trop Med Hyg 2012; 87: 281291. https://doi.org/10.4269/ajtmh.2012.11-0106

6. Ash A, Okello A, Khamlome B, Inthavong P, Allen J, Thompson RC. Controlling Taenia solium and soil transmitted helminths in a northern Lao PDR village: Impact of a triple dose albendazole regime. Acta Trop 2015. https://doi.org/10.1016/j.actatropica.2015.05.018

7. MoH L. Infectious and parasitic diseases. In: Diagnosis and Treatment in District Hospitals, Ministry of Health Lao PDR 2nd ed 2004: 109-181.

8. Hong ST, Choi MH, Kim CH, Chung BS, Ji Z. The Kato-Katz method is reliable for diagnosis of Clonorchis sinensis infection. Diagn Microbiol Infect Dis 2003; 47: 345-347. https://doi.org/10.1016/S07328893(03)00113-5

9. Ploner M. logistf: Firth's bias reduced logistic regression. R package version 1.22. http://CRANR-projectorg/package=logistf. 2016.

10. Li T, Ito A, Chen $X$, Long C, Okamoto M, Raoul F, Giraudoux P, Yanagida T, Nakao M, Sako Y, Xiao N, Craig PS. Usefulness of pumpkin seeds combined with areca nut extract in communitybased treatment of human taeniasis in northwest Sichuan Province, China. Acta Trop 2012; 124: 152-157. https://doi.org/10.1016/j.actatropica.2012.08.002

11. Flisser A, Vazquez-Mendoza A, Martinez-Ocana J, Gomez-Colin E, Leyva RS, Medina-Santillan R. Short report: evaluation of a self-detection tool for tapeworm carriers for use in public health. Am J Trop Med Hyg 2005; 72: 510-512. https://doi.org/10.4269/ ajtmh.2005.72.510

12. Bethony J, Chen J, Lin S, Xiao S, Zhan B, Li S, Xue H, Xing F, Humphries D, Yan W, Chen G, Foster V, Hawdon JM, Hotez PJ. Emerging patterns of hookworm infection: influence of aging on the intensity of Necator infection in Hainan Province, People's Republic of China. Clin Infect Dis 2002; 35: 1336-1344. https://doi. org/10.1086/344268

13. Bethony J, Brooker S, Albonico M, Geiger SM, Loukas A, Diemert D, Hotez PJ. Soil-transmitted helminth infections: ascariasis, trichuriasis, and hookworm. Lancet 2006; 367: 1521-1532. https://doi.org/10.1016/S0140-6736(06)68653-4

14. Jiraanankul V, Aphijirawat W, Mungthin M, Khositnithikul R, Rangsin R, Traub RJ, Piyaraj P, Naaglor T, Taamasri P, Leelayoova S. Incidence and risk factors of hookworm infection in a rural community of central Thailand. Am J Trop Med Hyg 2011; 84: 594-598. https://doi.org/10.4269/ajtmh.2011.10-0189

15. Olsen A, Samuelsen H, Onyango-Ouma W. A study of risk factors for intestinal helminth infections using epidemiological and anthropological approaches. J Biosoc Sci 2001; 33: 569-584. https:// doi.org/10.1017/S0021932001005697

16. Traub RJ, Robertson ID, Irwin P, Mencke N, Andrew Thompson
RC. The prevalence, intensities and risk factors associated with geohelminth infection in tea-growing communities of Assam, India. Trop Med Int Health 2004; 9: 688-701. https://doi.org/10.1111/ j.1365-3156.2004.01252.x

17. Phommasack B, Saklokham K, Chanthavisouk C, Nakhonesid-Fish V, Strandgaard H, Montresor A, Shuey DA, Ehrenberg J. Coverage and costs of a school deworming programme in 2007 targeting all primary schools in Lao PDR. Trans R Soc Trop Med Hyg 2008; 102: 1201-1206. https://doi.org/10.1016/j.trstmh.2008.04.036

18. World Health Organization. Control of Foodborne Trematode Infections: Report of a WHO Study Group. Geneva, Switzerland. World Health Organization. 1995, pp 1-157. https://apps.who. int/iris/handle/10665/41544

19. Laymanivong S, Hangvanthong B, Keokhamphavanh B, Phommasansak M, Phinmaland B, Sanpool O, Maleewong W, Intapan PM. Current status of human hookworm infections, ascariasis, trichuriasis, schistosomiasis mekongi and other trematodiases in Lao People's Democratic Republic. Am J Trop Med Hyg 2014; 90 : 667-669. https://doi.org/doi:https://doi.org/10.4269/ajtmh.13-0636

20. Sohn WM, Yong TS, Eom KS, Min DY, Lee D, Jung BK, Banouvong V, Insisiengmay B, Phommasack B, Rim HJ, Chai JY. Prevalence of Haplorchis taichui among humans and fish in Luang Prabang Province, Lao PDR. Acta Trop 2014; 136: 74-80. https:// doi.org/10.1016/j.actatropica.2014.04.020

21. 21. Yoon HJ, Ki M, Eom K, Yong TS, Chai JY, Min DY, Rim HJ, Sohn WM, Insisiengmay B, Phommasack B. Risk factors for Opisthorchis viverrini and minute intestinal fluke infections in Lao PDR, 2009-2011. Am J Trop Med Hyg 2014; 91: 384-388. https:// doi.org/10.4269/ajtmh.13-0596

22. Forrer A, Sayasone S, Vounatsou P, Vonghachack Y, Bouakhasith D, Vogt S, Glaser R, Utzinger J, Akkhavong K, Odermatt P. Spatial distribution of, and risk factors for, Opisthorchis viverrini infection in southern Lao PDR. PLoS Negl Trop Dis 2012; 6: e1481. https:// doi.org/10.1371/journal.pntd.0001481

23. Phongluxa K, Xayaseng V, Vonghachack Y, Akkhavong K, van Eeuwijk P, Odermatt P. Helminth infection in southern Laos: high prevalence and low awareness. Parasit Vectors 2013; 6: 328. https://doi.org/10.1186/1756-3305-6-328

24. Conlan J, Khounsy S, Inthavong P, Fenwick S, Blacksell S, Thompson RCA. A review of taeniasis and cysticercosis in the Lao People's Democratic Republic. Parasitol Int 2008; 57: 252-255. https://doi. org/http://dx.doi.org/10.1016/j.parint.2008.04.002

25. Chai JY, Yong TS, Eom KS, Min DY, Shin EH, Banouvong V, Insisiengmay B, Insisiengmay S, Phommasack B, Rim HJ. Prevalence of the intestinal flukes Haplorchis taichui and H. yokogawai in a mountainous area of Phongsaly Province, Lao PDR. Korean J Parasitol 2010; 48: 339-342. https://doi.org/10.3347/kjp.2010.48.4.339

26. Rim HJ, Sohn WM, Yong TS, Eom KS, Chai JY, Min DY, Lee SH, Hoang EH, Phommasack B, Insisiengmay S. Fishborne trematode metacercariae in luang prabang, khammouane, and saravane province, lao PDR. Korean J Parasitol 2013; 51: 107-114. https://doi.org/10.3347/kjp.2013.51.1.107

27. Pawlowski Z, Schultz MG. Taeniasis and cysticercosis (Taenia sagi- 
nata). Adv Parasitol 1972; 10: 269-343. https://doi.org/10.1016/ S0065-308X(08)60176-1

28. Hall A, Latham MC, Crompton DW, Stephenson LS. Taenia saginata (Cestoda) in western Kenya: the reliability of faecal examinations in diagnosis. Parasitology 1981; 83: 91-101. https://doi.org/10.1017/ S003118200005006X

29. Raoul F, Li T, Sako Y, Chen X, Long C, Yanagida T, Wu Y, Nakao M,
Okamoto M, Craig PS, Giraudoux P, Ito A. Advances in diagnosis and spatial analysis of cysticercosis and taeniasis. Parasitology 2013; 140: 1578-1588. https://doi.org/10.1017/S0031182013001303

30. Okello A, Ash A, Keokhamphet C, Hobbs E, Khamlome B, Dorny $\mathrm{P}$, Thomas L, Allen J. Investigating a hyper-endemic focus of Taenia solium in northern Lao PDR. Parasit Vectors 2014; 7: 134. https://doi.org/10.1186/1756-3305-7-134 